\title{
GEOLOGIA DOS GRUPOS BAMBUÍ, AREADO E MATA DA CORDA NA FOLHA PRESIDENTE OLEGÁRIO (1:100.000), MG: REGISTRO DEPOSICIONAL DO NEOPROTEROZÓICO AO NEOCRETÁCEO DA BACIA DO SÃO FRANCISCO
}

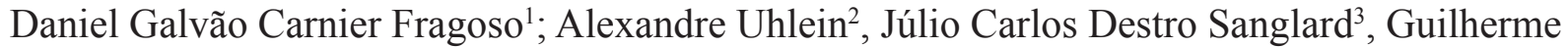 \\ Labaki Suckau ${ }^{3}$, Henrique Trópia Granja Guerzoni ${ }^{3} \&$ Paulo Henrique Faria ${ }^{3}$
}

\begin{abstract}
Resumo: Na Folha Presidente Olegário (SE.2E-Y-B-I), região noroeste de Minas Gerais, afloram essencialmente associações rochosas pertencentes à Bacia do São Francisco. Os litotipos mais antigos são atribuídos ao neoproterozóico e correspondem ao Grupo Bambuí. Nesta unidade foram reconhecidas as formações Lagoa do Jacaré (calcarenito, calcissiltito, biolitito, dolomito, marga e siltito), Serra da Saudade (siltito e lentes de calcissiltito) e Três Marias (arenito feldspático e siltito), sendo ainda acrescida da recém designada Formação Lagoa Formosa (siltito e diamictito). De maneira geral, estas associações litológicas correspondem a uma sedimentação marinha plataformal em bacia do tipo foreland. Em discordância com o Grupo Bambuí ocorrem espessos depósitos cretáceos pertencentes aos grupos Areado e Mata da Corda. Estas unidades têm sua gênese relacionada ao estiramento crustal produzido durante a abertura do Atlântico Sul. No Eocretáceo esta fase de tectônica distensiva foi responsável pela formação de um conjunto de falhamentos normais e pela reativação de algumas descontinuidades proterozóicas. A partir da movimentação de blocos se desenvolveu uma bacia receptora, com geometria graben-horst, onde depositaram-se as formações Abaeté (conglomerados, brechas e arenitos), Quiricó (siltito, argilito, folhelho e subordinadamente, arenito fino a grosso) e Três Barras (arenitos estratificados), pertencentes ao Grupo Areado. Por fim, rochas vulcânicas, piroclásticas e epiclásticas atribuídas ao Grupo Mata da Corda evidenciam uma atividade magmática produzida durante o Neocretáceo.
\end{abstract}

Palavras Chave: Litostratigrafia, Evolução Sedimentar, Bacia do São Francisco

\begin{abstract}
GEOLOGY OF BAMBUI, AREADO AND MATA DA CORDA GROUPS IN THE PRESIDENTE OLEGÁRIO SHEET (1:100.000), MG: NEOPROTEROZOIC TO LATE CRETACEOUS DEPOSITIONAL RECORD OF THE SÃO FRANCISCO BASIN. In Presidente Olegario Sheet (SE.2E-Y-B-I), northwestern of Minas Gerais state, occurs essentially sedimentary rocks related to São Francisco Basin. The oldest rocks are assigned to the Neoproterozoic and correspond to the Bambuí Group. In this unit were recognized the following formations: Lagoa do Jacaré (calcarenite, calcisiltite, biolithite, dolomite, marl and siltstone), Serra da Saudade (siltstone and lenses of calcisiltites) and Três Marias (feldspathic sandstone and siltstone), with the addition of the newly designated Lagoa Formosa Formation (siltstone and diamictite). In general, these lithological associations represent a marine shelf sedimentation in a foreland basin. In unconformity with the Bambuí Group occur thick cretaceous deposits of the Areado and Mata da Corda groups. These units have their genesis related to crustal stretching produced during the opening of the South Atlantic. At the Early Cretaceous, extensional tectonic was responsible for the development of a normal faults system and reactivation of some proterozoic discontinuities. With the displacement of blocks a receiving basin, with horst-graben geometry, was developed, taking the deposition of the Abaeté (conglomerates, breccias and sandstones), Quiricó (siltstone, mudstone, shale and subordinate sandstone) e Três Barras (stratified sandstones) formations, in Areado Group. Finally, volcanic, pyroclastic and epiclastic rocks of the Mata da Corda Group was deposited, showing a intense magmatic activity in Late Cretaceous.
\end{abstract}

Keywords: Lithostratigraphy, Sedimentary Evolution, São Francisco Basin

\section{INTRODUÇÃO}

A Bacia do São Francisco corresponde a uma bacia intracratônica que recobre o embasamento do Cráton do São Francisco. Abrange áreas dos estados de Minas Gerais, Bahia, Goiás e Tocantins. O preenchimento desta bacia apresenta uma evolução poli-histórica representada por unidades estratigráficas com características distintas e idades que variam do Paleo/Neoproterozóico ao Cretáceo Superior (Alkmim $\&$ Martins-Neto 2001).

A área coberta pela Folha Presidente Olegário (SE.2E-Y-B-I), localizada na porção noroeste do estado de Minas Gerais, é delimitada pelas coordenadas 
geográficas $46^{\circ} 00^{\circ} 00^{\prime \prime}$ e $46^{\circ} 30^{\circ} 00^{\prime \prime}$ de longitude oeste e $18^{\circ} 00^{`} 00^{\prime \prime}$ e $18^{\circ} 30^{\prime} 00^{\prime \prime}$ de latitude sul. Situa-se no Cráton do São Francisco, próximo ao seu limite com a Faixa Brasília (Figura 1). Os litotipos aflorantes na região pertencem à Bacia do São Francisco e correspondem a associações rochosas neoproterozóicas do Grupo Bambuí e espessas coberturas cretáceas que compõem os grupos Areado e Mata da Corda (Figura 2). Estas unidades representam, pelo menos, duas etapas de sedimentação com contextos bacinais bem distintos. A primeira, correspondente ao Grupo Bambuí, caracteriza-se como uma sucessão predominantemente siliciclástica, com termos carbonáticos subordinados, sedimentados em um ambiente marinho plataformal, em uma provável bacia do tipo foreland, desenvolvida durante a edificação da Faixa Brasília. Compilações sobre a estratigrafia e a evolução geológica do Grupo Bambuí são apresentadas por Uhlein et al. (2004) e Lima (2005).

A segunda etapa de sedimentação está relacionada ao estiramento crustal produzido durante a abertura do Atlântico sul no Eocretáceo. Esta fase de tectônica distensiva deu origem a uma bacia receptora na forma de graben-horst, onde se depositaram as unidades do Grupo Areado, que corresponde a uma sedimentação predominantemente continental. Por fim, durante o
Neocretáceo, uma grande atividade magmática produziu rochas vulcânicas (efusivas e piroclásticas) ultramáficas alcalinas, e rochas epiclásticas, originadas a partir da erosão dos edifícios vulcânicos. Estes litotipos são atribuídos ao Grupo Mata da Corda. Uma revisão da estratigrafia e dos sistemas deposicionais de todas as unidades que constituem a cobertura fanerozóica do Cráton do São Francisco é apresentada por Campos \& Dardenne (1997a).

Este trabalho consiste na compilação dos resultados obtidos durante o mapeamento geológico da Folha Presidente Olegário 1:100.000 (SE.2E-YB-I - Figura 3) realizado no ano de 2009 no âmbito do convênio CODEMIG - CPMTC - UFMG, bem como considerações a respeito da estratigrafia das unidades aflorantes e contribuições para a análise da evolução da Bacia do São Francisco na região.

\section{GEOLOGIA DA FOLHA PRESIDENTE OLEGÁRIO: CONSIDERAÇÕES INICIAIS}

O mapeamento geológico da Folha Presidente Olegário foi realizado a partir da descrição sistemática de 798 pontos, onde se objetivou o levantamento estratigráfico a partir da descrição de litofácies, e a caracterização estrutural das unidades mapeadas.

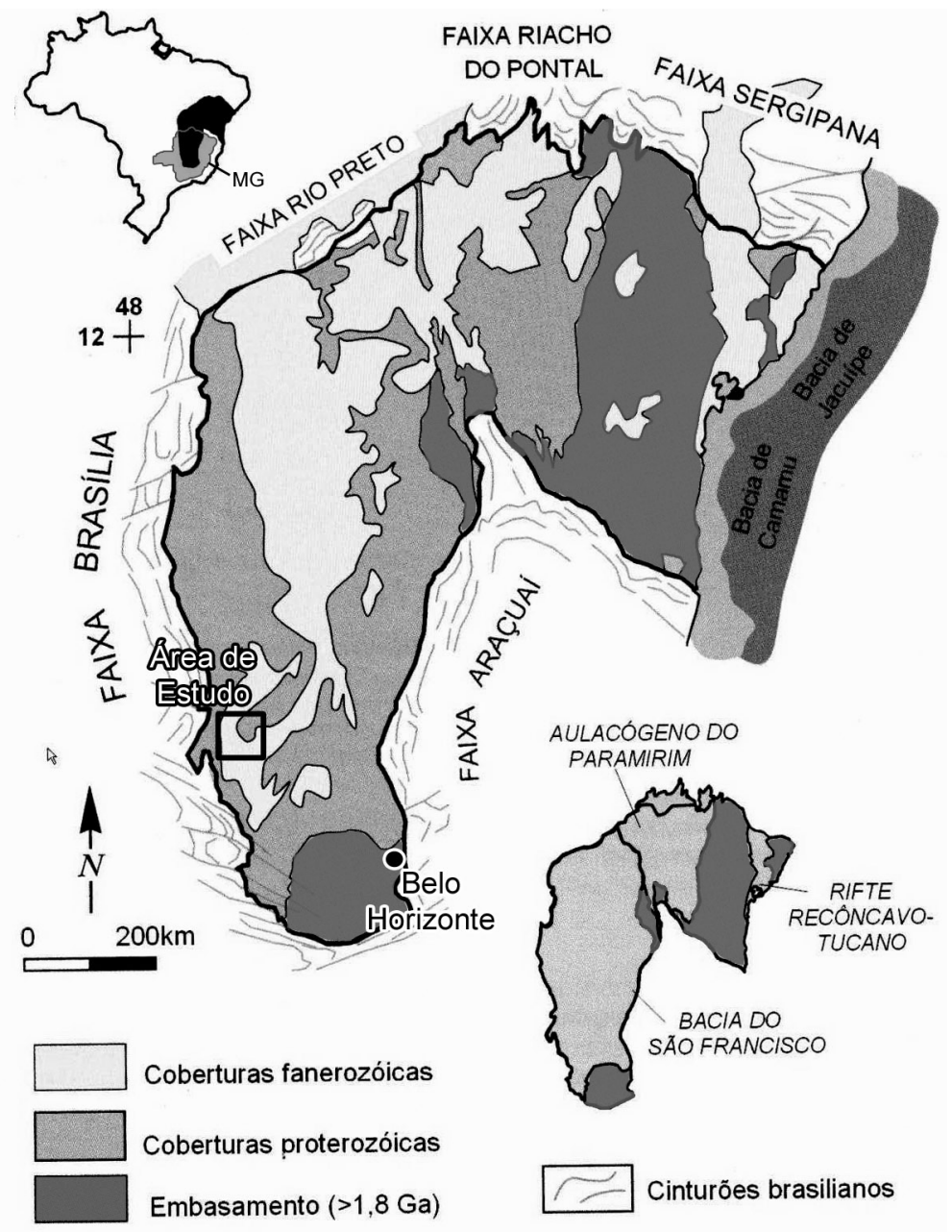

Figura 1. Localização geográfica e contexto geológico da área de estudo (Alkmim et al. 1993). 


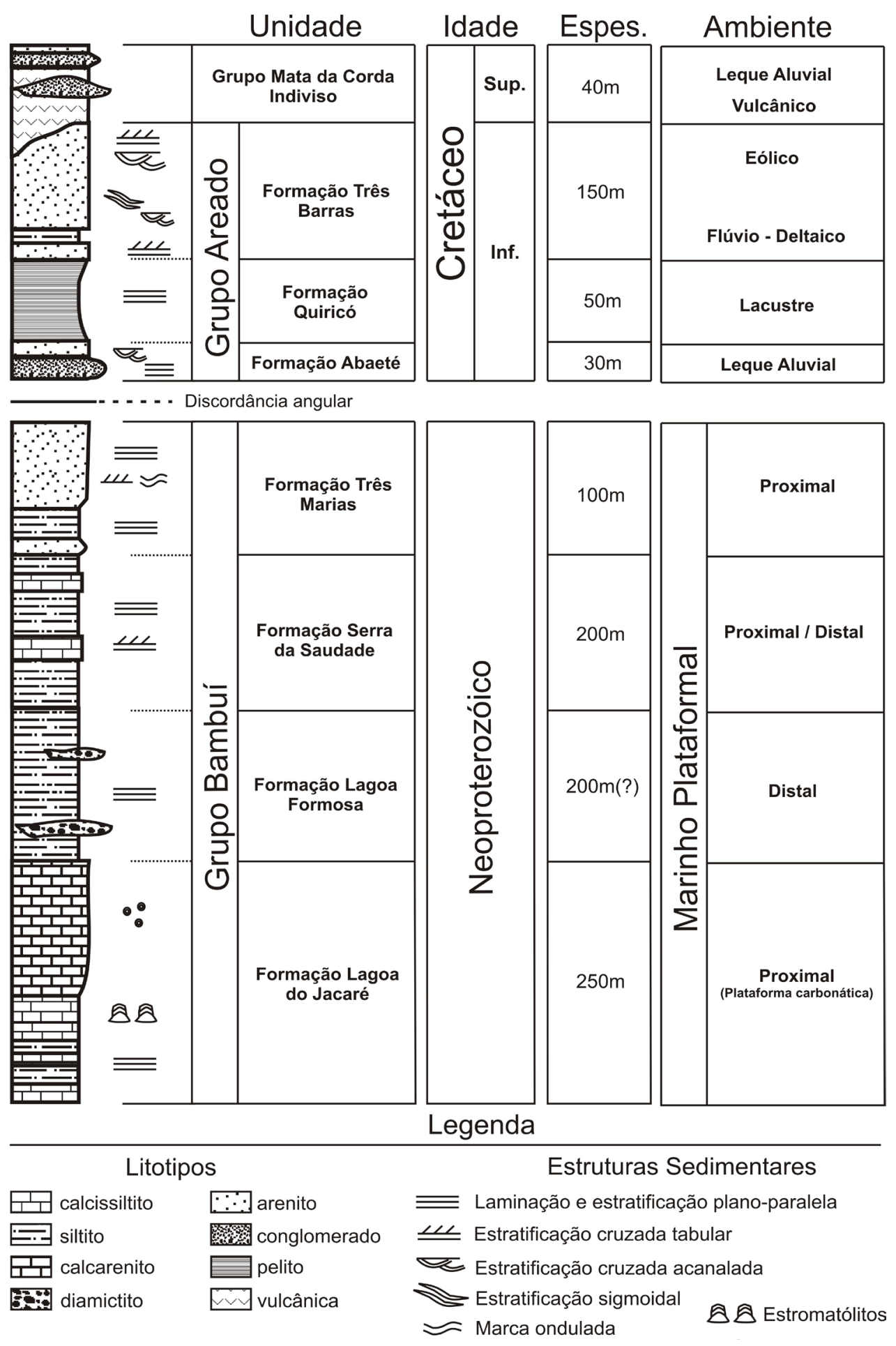

Figura 2. Coluna litoestratigráfica da Folha Presidente Olegário

Para o Grupo Bambuí foram reconhecidas as formações Lagoa do Jacaré, Serra da Saudade e Três Marias, sendo ainda acrescido da recém designada Formação Lagoa Formosa (Uhlein et al., 2010).

O contato de topo do Grupo Bambuí com o Grupo Areado é marcado por uma superfície erosiva, contínua e irregular. No Grupo Areado foram reconhecidas as formações Abaeté, Quiricó e Três Barras.

O Grupo Mata da Corda foi mantido indiviso devido a relação de alternância e forte interdigitação de suas formações Patos e Capacete, dificultando a sua individualização na escala 1:100.000.

Sobre todas as unidades ocorrem ainda sedimentos inconsolidados de natureza elúvio-coluvionar, freqüentemente lateritizados, de idade PaleógenaNeógena.

\section{GRUPO BAMBUÍ}

FORMAÇÃO LAGOA DO JACARÉ - Constitui a unidade basal do Grupo Bambuí na região. Corresponde a uma seqüência predominantemente carbonática, 


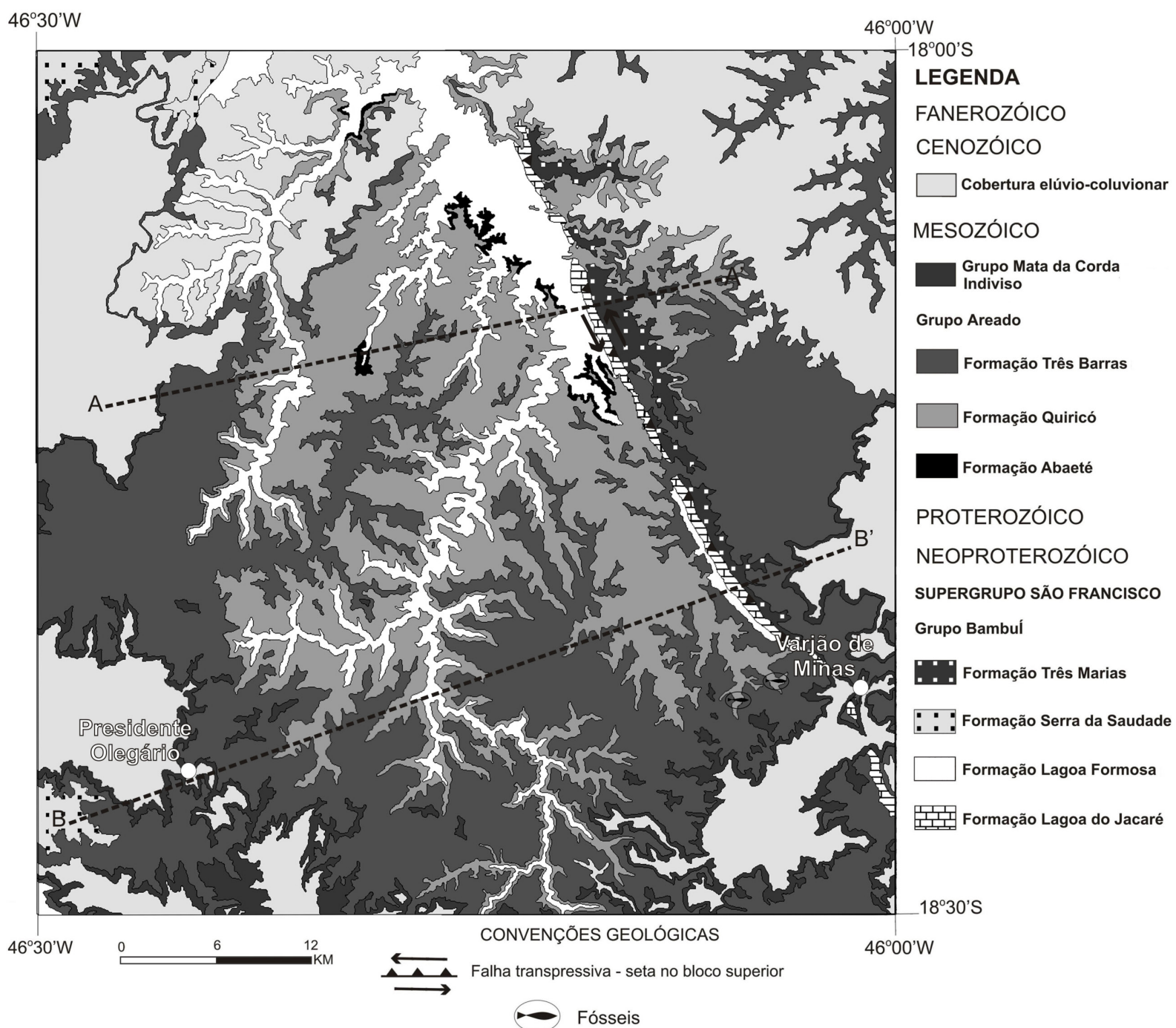

Figura 3. Mapa geológico simplificado da Folha Presidente Olegário, MG.

intensamente deformada, com espessura da ordem de $250 \mathrm{~m}$. Aflora em um faixa estreita e contínua, de direção NNW-SSE, na porção centro-leste do mapa. Em campo, os afloramentos são facilmente identificados devido à morfologia de cristas elevadas. Sua ocorrência está associada à Falha de Galena, que corresponde ao empurrão desta unidade sobre os litotipos da Formação Três Marias.

Esta unidade é composta principalmente por calcarenito, localmente oolítico. Ocorrem subordinadamente, calcissiltito, biolitito, marga e siltito. Observa-se, em todos os litotipos, estruturas de laminação e/ou estratificação plano-paralela e, localmente, laminação cruzada.

O calcissiltito ocorre na porção basal da unidade. Apresenta laminação plano-paralela e cor cinza claro ou rósea. Observam-se porções dolomitizadas e silicificadas. Subordinadamente afloram siltito, marga e calcarenito fino cinza-escuro.

O biolitito (Figura 4a) é identificado na porção intermediária. Corresponde a construções estromatolíticas colunares, finamente laminadas, com ramificação paralela. O material intercolunar é composto por calcissiltito, cinza-claro, com alguns fragmentos das próprias construções.

No topo da seqüência predomina calcarenito, cinza-escuro, por vezes oolítico, muito deformado e recristalizado.

A melhor exposição desta unidade ocorre nas proximidades da confluência do Rio da Prata com o Rio Andrequicé. Nesta região, a Formação Lagoa do Jacaré encontra-se assentada sobre um arenito fino a grosso, por vezes conglomerático, que apresenta marcas onduladas assimétricas e estratificações plano-paralelas e cruzadas tabulares. Devido à sua ocorrência restrita a posição estratigráfica destes litotipos ainda é duvidosa, podendo se tratar de uma unidade mais antiga, talvez correlacionável ao Grupo Paranoá.

FORMAÇÃO LAGOA FORMOSA - Corresponde à unidade neoproterozóica de maior extensão em área na Folha Presidente Olegário. Aflora em toda a porção central ao longo dos vales encaixados. Sua espessura é de difícil determinação devido aos efeitos da deformação - dobras e repetições por falhamentos - que muitas vezes estão encobertas pelos sedimentos cretáceos do Grupo Areado. Estima-se aqui uma 
espessura na ordem de $200 \mathrm{~m}$.

É composta predominantemente por siltito (Figura 4b), com pequenas intercalações de siltito argiloso, argilito e, em menor quantidade, arenito. Apresentam laminação e estratificação plano-paralela marcadas pela variação granulométrica dos sedimentos e/ou pela mudança de cor. Em geral os afloramentos encontram-se intensamente fraturados e bastante intemperizados, exibindo colorações que variam de bege a rósea. Quando frescos apresentam coloração verde escuro a cinza. Associado ao siltito ocorre, subordinadamente, diamictito de matriz silto-argilosa e arcabouço composto por seixos e blocos subangulosos de siltito laminado e maciço (Figura 4c).

As melhores exposições desta unidade ocorrem ao sul da Folha Presidente Olegário, nas proximidades de Carmo do Paranaíba e Lagoa Formosa. Nesta região são encontrados, associados ao siltito, lentes e camadas de arenito, calcário, jaspilito e conglomerados. O diamictito apresenta-se em maior expressão e é composto por clastos maiores (grânulo a matacão) de siltito, arenito feldspático e, subordinadamente, calcário, metarenito, conglomerado e granitóide. Nesta região encontram-se, localmente, pelitos verdes e diamictitos de matriz esverdeada.

FORMAÇÃO SERRA DA SAUDADE - Aflora apenas na porção oeste do mapa e apresenta espessura na ordem de $200 \mathrm{~m}$. Aparentemente, esta unidade está estratigraficamente acima da Formação Lagoa Formosa, entretanto, as relações entre estas unidades ainda não foram bem definidas, sendo interpretado aqui um contato transicional, representado por uma mudança na associação litológica.

O litotipo predominante corresponde a um siltito, por vezes argiloso, com constante laminação planoparalela. Os afloramentos encontram-se normalmente bem intemperizados, o que confere à rocha coloração ocre a rósea. Calcissiltito e, subordinadamente, calcarenito fino ocorrem em lentes de no máximo $1 \mathrm{~m}$. Apresentam estratificações plano-paralelas e cruzadas tabulares. Intercalado no siltito ocorrem também lentes métricas de verdete, que corresponde a um siltito verde enriquecido em potássio, podendo apresentar também altos teores de fósforo. A coloração esverdeada devese a presença do filossilicato potássico glauconita, conforme Lima et al. (2007). Este litotipo característico se assemelha com os pelitos verdes e diamictitos de matriz esverdeada observados na Formação Lagoa Formosa, o que pode representar uma correlação entre estas unidades.

FORMAÇÃO TRÊS MARIAS - A ocorrência desta formação está restrita à porção leste da principal estrutura identificada na região - a Falha de Galena. Apresenta espessura na ordem de $50 \mathrm{~m}$. Aflora preferencialmente ao longo dos vales do Rio Andrequicé e suas drenagens, bem como nos vales das drenagens do Ribeirão Quiricó.

É composta predominantemente por sub-arcósio e arenito feldspático grauvaquiano cinza-escuro, fino a médio, com camadas plano paralelas maciças ou laminadas (Figura 4d). Na porção inferior ocorrem ainda intercalações pelíticas (siltito e siltito argiloso) entre as camadas arenosas. Para o topo passa a dominar as frações areníticas.

No arenito são freqüentes marcas onduladas e laminações cruzadas. Contudo, predominam as camadas tabulares centimétricas a decimétricas de arenito maciço ou com laminação plano-paralela. Em lâmina delgada nota-se a freqüente presença de matriz argilosa que, em alguns casos, confere classificação grauvaca. Outra feição comum nos afloramentos de arenito é disjunção esferoidal. Essa forma de alteração intempérica é provavelmente favorecida pelo sistema de fraturas existente, somado às descontinuidades da própria estratificação sedimentar e caráter maciço da rocha.

ARCABOUÇO ESTRUTURAL-O acervo estrutural observado no Grupo Bambuí é relativamente restrito. A principal estrutura observada, denominada de Falha de Galena, corresponde a uma descontinuidade de alto ângulo de origem compressiva e direção aproximada NW-SE. Esta estrutura divide a região em dois domínios estruturais (1 e 2 - Figura 5) com padrões diferenciados pela intensidade de deformação, pela orientação das dobras e geometria das mesmas.

O Domínio 1 corresponde ao setor de deformação mais intensa. Apresenta um amplo sistema de dobramentos flexurais, com dobras cilíndricas harmônicas e também com estilo em chevron, que variam de apertadas a fechadas com caimento de eixo predominantemente para sudoeste (Figura 5a) e vergência para leste (Figura $5 \mathrm{~B})$. Associado às dobras, comumente são observadas fraturas do tipo "ac" (perpendiculares ao eixo "b" - Figura 5C), estruturas de deslizamento interestratal e falhas de empurrão com pequenos rejeitos. Localmente observam-se fraturas de tensão centimétricas, distribuídas em leque nas zonas de charneira, preenchidas por calcita. Nas proximidades da Falha de Galena ocorrem dobras desarmônicas em cúspide.

No Domínio 2 são observados acamamentos subhorizontais e dobras suaves e abertas. Entretanto, nas proximidades do seu limite com o Domínio 1, há variação do mergulho do acamamento e ocorrência de dobras fechadas (Figura 5D). A distribuição das dobras e a variação de suas formas caracterizam uma diminuição da deformação de oeste para leste. O tipo mais comum de dobra é a de isógonas convergentes, com as mesmas perpendiculares às camadas, tipo "1B" de acordo com a classificação de Ramsay (1967).

A cinemática da Falha de Galena ainda carece de mais estudos, todavia, a análise parcial determinou que esta estrutura apresenta uma movimentação oblíqua sinistral. A relação angular entre seu traço retilíneo, os eixos das dobras e a vergência das mesmas, mais as inflexões e curvaturas que ocorrem nas proximidades da falha, indicam que o setor oeste foi empurrado contra $o$ leste ao mesmo tempo que deslocava-se sinistralmente pela grande descontinuidade (Figura 6). 

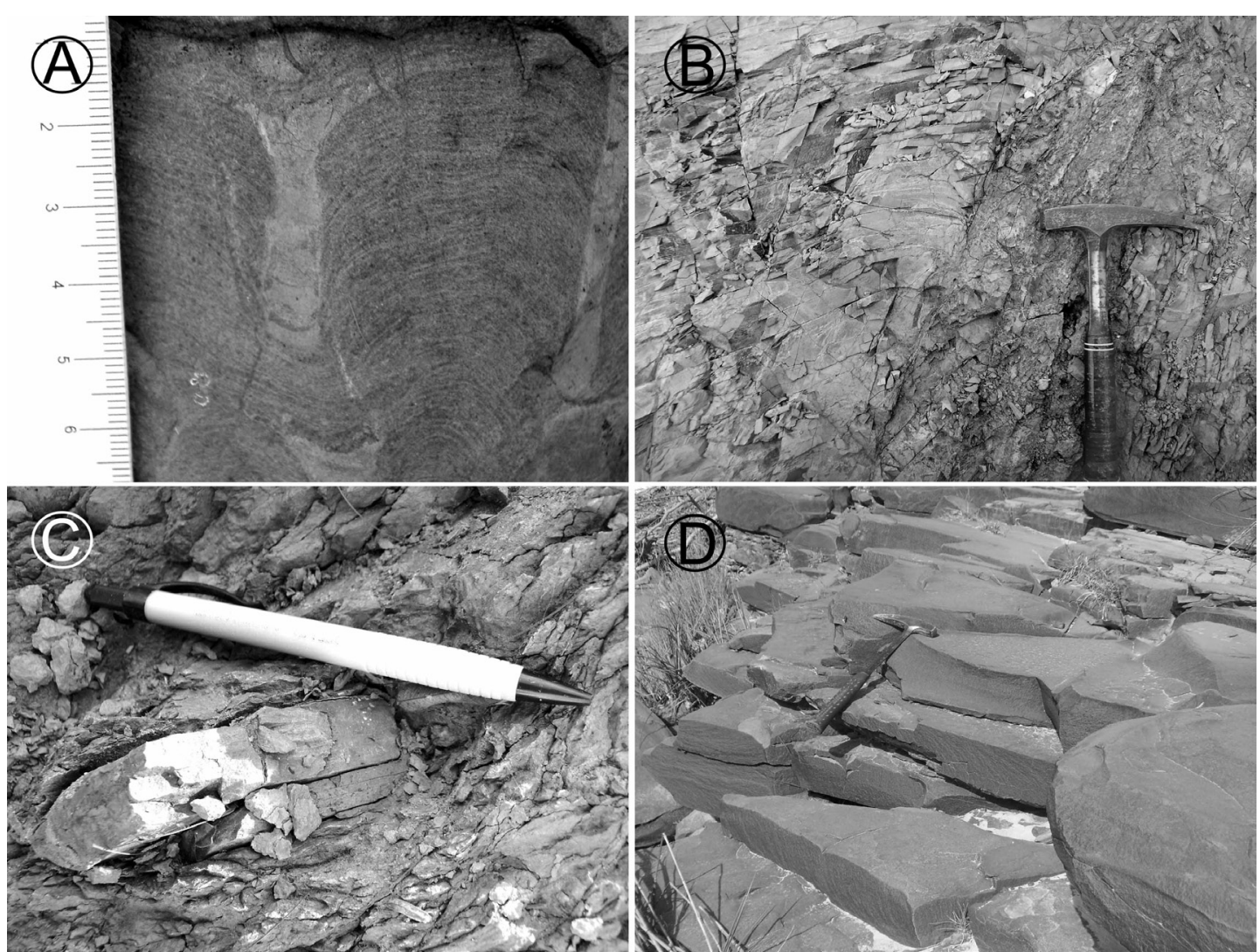

Figura 4. Grupo Bambui: A - Colunas estromatolíticas com ramificação lateral da Formação Lagoa do Jacaré; B - Siltito dobrado da Formação Lagoa Formosa apresentando falhas reversas com vergência para leste; C - Diamictito da Formação Lagoa Formosa - Clasto de siltito laminado disperso em matriz silto-argilosa; D - Camadas maciças de arenito feldspático grauvaquiano da Formação Três Marias.

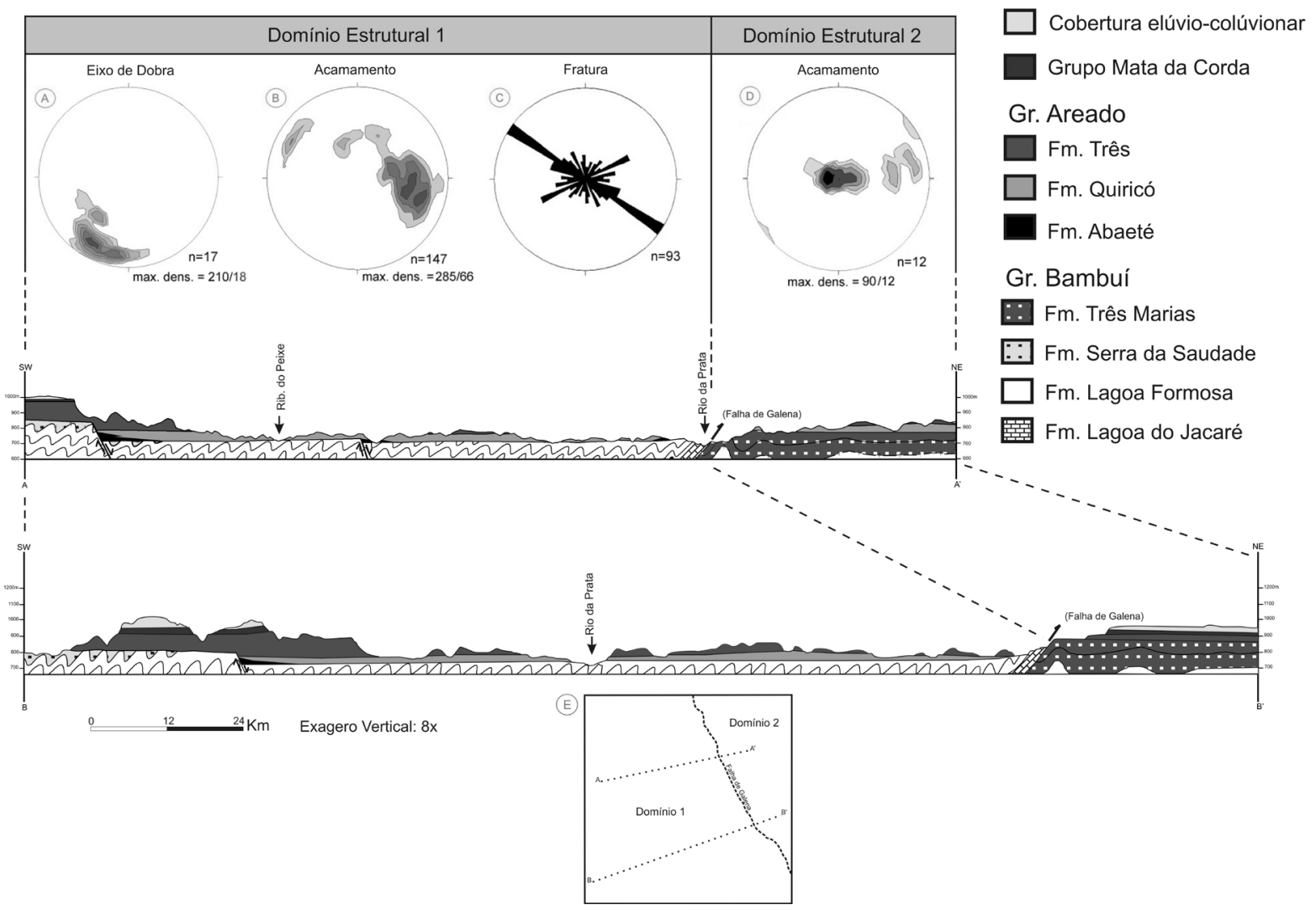

Figura 5. Seções geológicas A-A'e B-B'mostrando a separação dos domínios estruturais do Grupo Bambuí: A-Diagrama de densidade com medidas de eixos de dobra do domínio 1; B-Diagrama de densidade de pontos polares das medidas de acamamento do domínio 1; $C$ Diagrama de rosetas com medidas de fratura do domínio 1; D-Diagrama de densidade de pontos polares das medidas de acamamento do domínio 2; D - Divisão em área dos domínios estruturais na Folha Presidente Olegário 


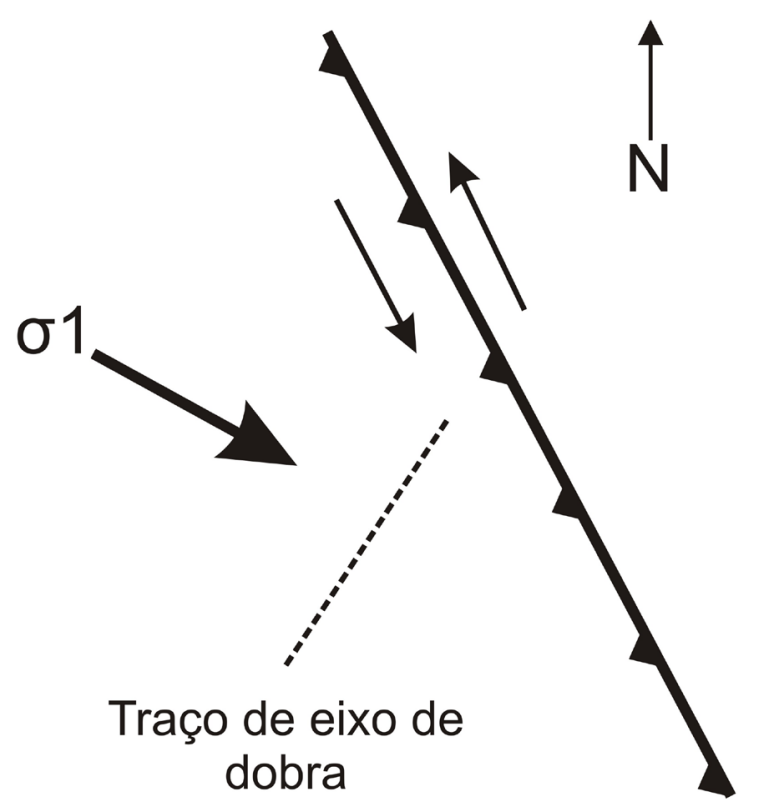

Falha de Galena

Figura 6. Interpretação da cinemática da Falha de Galena na Folha Presidente Olegário a partir da relação angular entre o traço da falha, os eixos das dobras e a vergência das mesmas.

Diversos autores (eg. Kattah 1991; Sawasato 1995) relatam ainda uma reativação normal para a Falha de Galena durante o Cretáceo. Tal reativação teria controlado, pelo menos parcialmente, a sedimentação do Grupo Areado. Outras estruturas de natureza distensiva também ocorrem impostas sobre os sedimentos deformados do Grupo Bambuí. Pequenas falhas normais de rejeito centimétrico, que formam verdadeiros sistemas de horsts e grabens em escala de afloramento, são encontrados em ambos os domínios estruturais do Grupo Bambuí (Figura 7).

\section{AREADO}

FORMAÇÃO ABAETÉ - Aflora de maneira descontínua na porção central da área na forma de cunhas clásticas. Apresenta espessura máxima da ordem de 30 metros. O seu contato inferior com rochas pelíticas da Formação Lagoa Formosa constitui uma discordância angular e erosiva.

O litotipo predominante corresponde a arenitos líticos, por vezes conglomeráticos, variando até termos sub-arcosianos. Apresenta coloração branca a vermelhada e exibe estratificação cruzada acanalada e estratificação/laminação plano-paralela. Subordinadamente há intercalações de camadas tabulares de ortoconglomerado polimítico, com matriz arenosa e clastos de siltito bege (predominante), quartzo leitoso e quartzito branco, subangulosos a subarredondados, com tamanhos que variam de seixo a bloco (Figura 8A). Próximo à região da Falha de Galena ocorrem ainda lentes de brecha clasto suportada, monomítica, com clastos tamanho seixo a matacão (até $40 \mathrm{~cm}$ ) de calcário cinza escuro, por vezes oolítico.

FORMAÇÃO QUIRICÓ - Ocupa grande parte em área do mapa, concentrando-se na porção centro-sul. Sua exposição a leste da Falha de Galena é restrita e nas extremidades do mapa é ausente. Possui espessura máxima de cerca de 50 metros. Ocorre interdigitada com a Formação Abaeté, com a qual é parcialmente sincrônica. Em alguns locais assenta-se em discordância angular e erosiva sobre o Grupo Bambuí.

Uma grande variedade de rochas predominantemente pelíticas, e subordinadamente areníticas, domina as ocorrências da unidade na região. As frações areníticas predominam nas proximidades dos contatos inferior e superior com as unidades adjacentes. Na porção intermediaria ocorrem: ritmito areno-pelítico com estratificação linsen e marcas de ondas; folhelho avermelhado, localmente com concreções carbonáticas; pelito arenoso laminado; e siltito argiloso maciço.
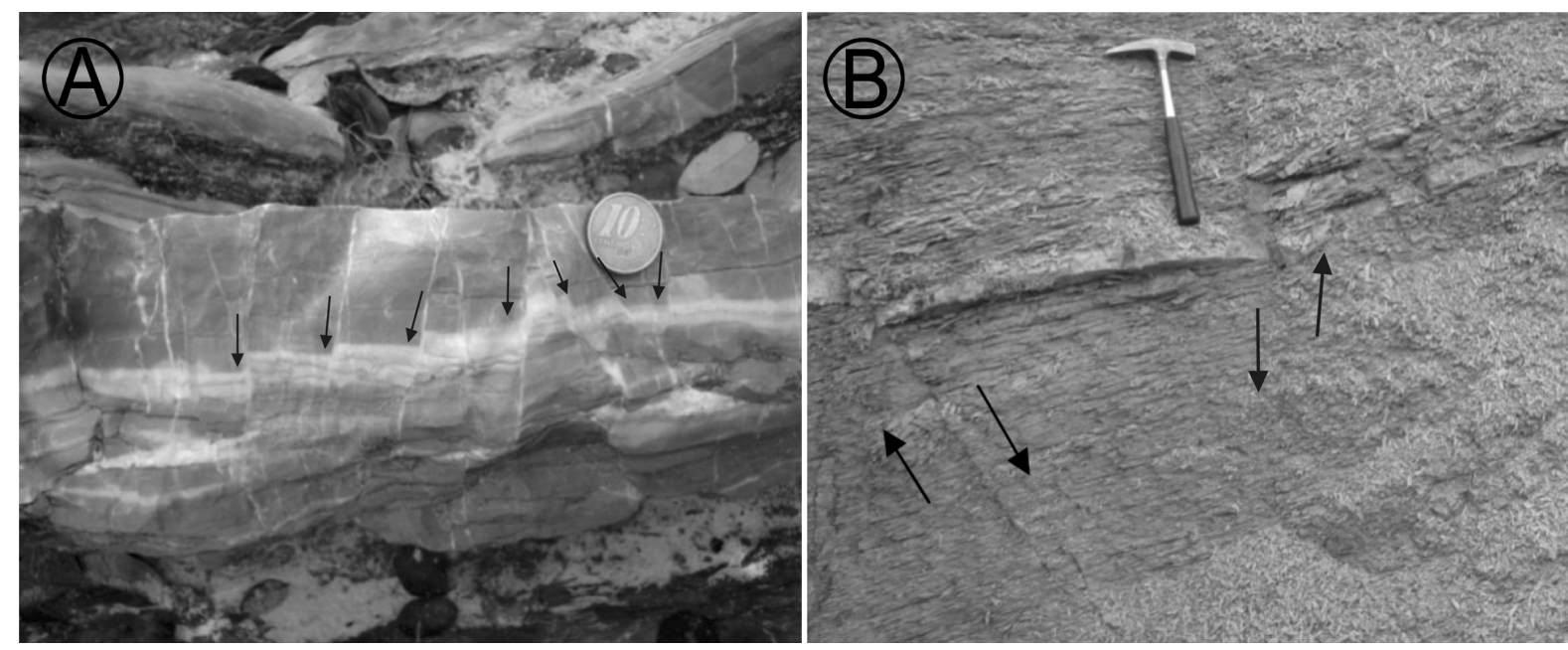

Figura 7. Sistema de falhas normais.

A- Calcário da Formação Lagoa do Jacaré (Domínio 1);

B-) Siltitos da Formação Três Marias (Domínio 2). 
Próximo a sede da cidade de Varjão de Minas, nas drenagens do Ribeirão Quiricó, encontra-se intercalada a folhelhos vermelhos, uma camada de aproximadamente $2 \mathrm{~m}$ de folhelho negro, rico em matéria orgânica, contendo fósseis de peixes do gênero Dastilbe (Figura 8B).

FORMAÇÃO TRESS BARRAS-Constitui a unidade de maior expressão em área na Folha Presidente Olegário. Apresenta espessura máxima na ordem de 150 metros. Pode ser subdividida nas porções inferior e superior.

A porção inferior corresponde a uma associação de arenito com subordinadas contribuições pelíticas. Nas frações arenosas observam-se estratificações planoparalela e cruzadas tabular, acanalada, tangencial e sigmoidal (Figura 8C). Localmente são encontradas marcas onduladas e estruturas convolutas. Os arenitos são geralmente mal selecionados, variando de fino a grosso, raramente conglomerático. As frações finas associadas correspondem a pelito vermelho maciço, localmente arenoso, ritmito areno-pelítico e argilito com cores variadas.

A porção superior da Formação Três Barras aflora principalmente nas escarpas das chapadas, nas regiões leste e oeste da folha, onde ocorre diretamente sobre o Grupo Bambuí. Caracteriza-se por um espesso pacote de arenito cuja principal característica é a bimodalidade, conferida por alternâncias de laminas de areia grossa e areia média a fina (Figura 8D). Apresenta estratificações plano-paralela e cruzadas tabular, acanalada e tangencial, todas com sets métricos (Figura 8E). Observa-se ainda, intercaladas no arenito, raras camadas de argilito vermelho com gretas de contração.

Próximo ao contato superior com o Grupo Mata da Corda são observados nos arenitos deformações que provocam verticalização e desorganização na
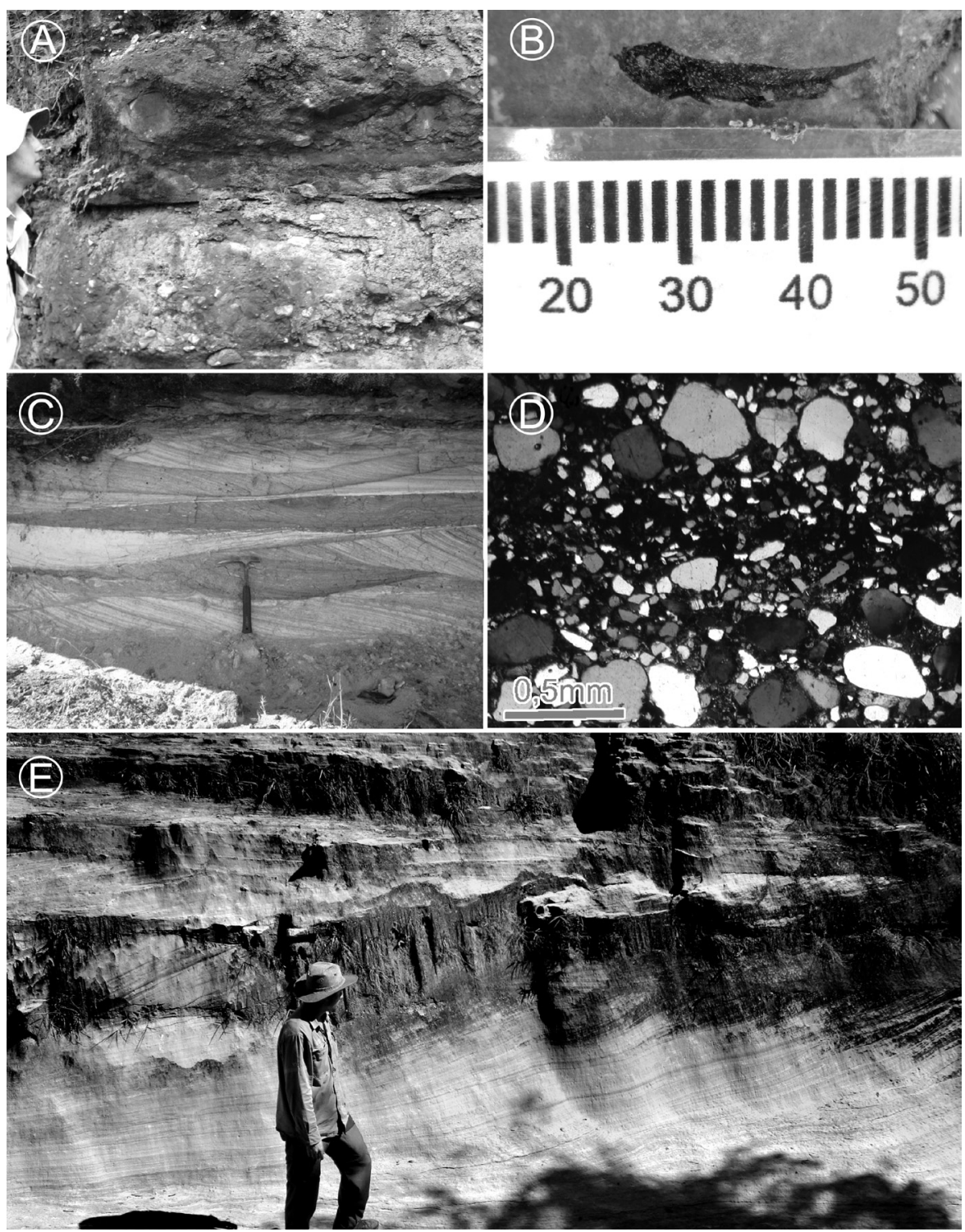

Figura 8. Grupo Areado: A - Camadas tabulares de ortoconglomerádo polimítico - fácies de leque aluvial da Formação Abaeté; B - Fóssil de peixe do gênero Dastilbe encontrado em camadas de folhelho negro da Formação Quiricó; C-Arenito com estratificações cruzadas acanalada e tangencial - fácies flúvio-deltáico da Formação Três Barras; D - Fotomicrografia exibindo bimodalidade no arenito com lâminas de areia fina, com grãos angulosos, e lâmina de areia média, com grãos arredondados -fácies eólica da Formação Três Barras ; CArenito exibindo estratificação cruzada tangencial com sets métricos - fácies eólica da Formação Três Barra 
estratificação, por vezes formando dobras desarmônicas. Mais raramente são encontradas ainda fraturas silicificadas, drusas de quartzo cristalino e bombas vulcânicas.

\section{GRUPO MATA DA CORDA}

Ocorre principalmente associado às encostas das chapadas nas porções sudoeste e sudeste, em altitudes que variam de 850 a $1000 \mathrm{~m}$. Abrange aproximadamente $10 \%$ da área da folha. É representado por uma alternância de rochas vulcânicas e epiclásticas. Estes litotipos são pertencentes, respectivamente, às formações Patos e Capacete. Entretanto, a alternância e a forte interdigitação destas unidades dificultam a sua individualização na escala 1:100.000.

Os termos vulcânicos correspondem a rochas alcalinas máficas a ultramáficas afaníticas, por vezes porfiríticas, de natureza efusiva e piroclástica. Subordinadamente ocorrem rochas subvulcânicas de conduto. Composicionalmente podem ser classificadas como kamafugitos (Moraes et al. 1987). Apresentam coloração cinza escuro quando frescas, e tonalidades avermelhadas e esverdeadas quando alteradas. Os melhores afloramentos desta unidade estão na porção sudoeste do mapa, na estrada que liga Presidente Olegário a Patos de Minas. Nas demais localidades estas rochas estão em estágio avançado de intemperismo. Em lâminas delgadas são observados fenocristais e raros xenólitos emersos em uma matriz de finos cristais de clinopiroxênio. Os fenocristais são de perovskita e pseudomorfos de olivina, enquanto os xenólitos correspondem a cumulados de piroxênio com possível alteração de feldspatóide no centro (Figura 9A e B).

Os termos sedimentares desta unidade são representados por paraconglomerado e arenito lítico originados a partir da erosão das rochas vulcânicas. O paraconglomerado apresenta matriz areno-argilosa, de coloração vermelha a branca, e clastos tamanho grânulo a matacão, arredondados a subangulares, compostos principalmente por rochas vulcânicas (Figura 9C).

\section{EVOLUÇÃO SEDIMENTAR}

A disposição do Grupo Bambuí é relacionada ao desenvolvimento de um ambiente marinho plataformal cuja sedimentação foi fortemente controlada pelas variações do nível do mar e pelo soerguimento da Faixa Brasília que, pelo menos localmente, foi responsável pela instalação de uma bacia foreland (Chang et al.1988; Castro 1997; Martins-Neto et al.1997; MartinsNeto \& Alkmim 2001; Baptista 2004).

O reconhecimento e a interpretação das associações litológicas do Grupo Bambuí revelam a existência de pelo menos três estágios de sedimentação:

I - Formação Lagoa do Jacaré: Sedimentação em uma plataforma carbonática com contribuições siliciclásticas subordinadas. A porção basal desta unidade, composta pela associação de calcissiltitos e pelitos, sugere uma deposição em águas calmas
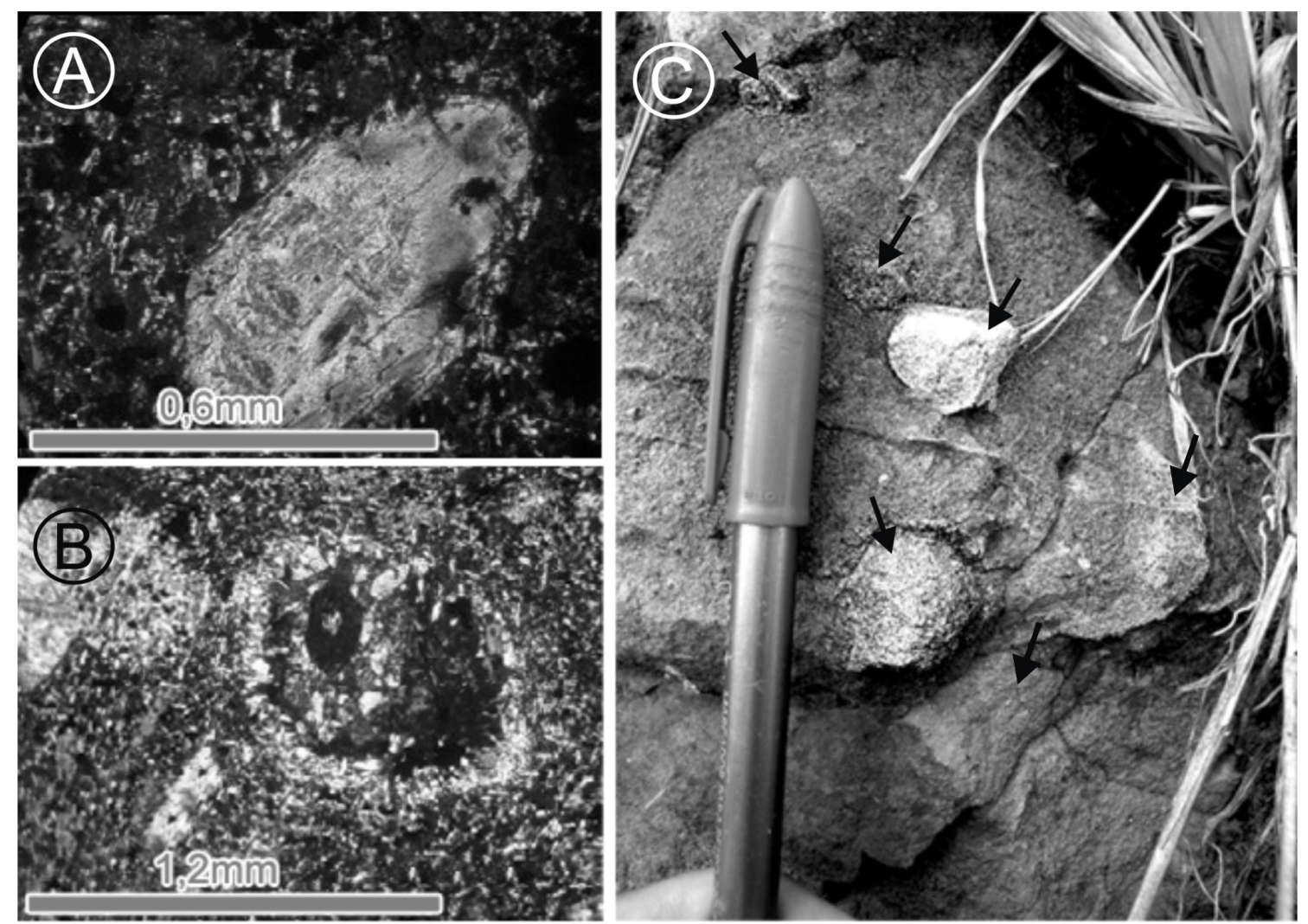

Figura 9. Grupo Mata da Corda - Fotomicrografias de rochas vulcânicas do Grupo Mata da Corda: A - Pseudomorfo de olivina e B Xenólito apresentando piroxênio nas bordas e alteração de feldspatóide no centro; C-Conglomerado matriz suportado com clastos de rocha vulcânica (setas); 
relacionada ao subambiente de rampa profunda, longe da influência de correntes. Já as porções intermediaria e de topo estão relacionados a subambientes proximais com pouca ou nenhuma contribuição terrígena. A presença de biolitito e calcarenito oolítico sugere uma sedimentação em águas rasas, com forte precipitação carbonática e influências de retrabalhamento por ondas ou correntes de marés.

II - Formações Lagoa Formosa e Serra da Saudade: Estabelecimento de uma sedimentação siliciclástica, predominantemente fina, provavelmente relacionada a uma elevação do nível do mar e aumento do aporte sedimentar, que inibiram a precipitação carbonática. Durante este estágio, fluxos gravitacionais foram responsáveis pela deposição dos diamictitos da Formação Lagoa Formosa. Estes fluxos podem ter sido induzidos pela movimentação tectônica gerada durante o soerguimento orogenético da Faixa Brasília a oeste. Os diamictitos são mais expressivos e apresentam clastos maiores (até matacão) na região adjacente a sul da Folha Presidente Olegário, nas proximidades de Carmo do Paranaíba e Lagoa Formosa. Na área mapeada dominam seus correspondentes laterais distais, com clastos no tamanho máximo de bloco associado a litofácies pelíticas com intercalações arenosas. A Formação Serra da Saudade registra a sedimentação em períodos de quiescência tectônica durante este estágio. Nas regiões mais rasas foram formadas as lentes carbonáticas. Já as ocorrências de verdete ainda não apresentam significado sedimentológico bem estabelecido. Segundo Lima et al. (2007), a glauconita é um mineral diagenético que indica um ambiente de sedimentação em plataforma externa com baixo aporte detrítico, em um micro-ambiente redutor. Entretanto, os autores associam as características texturais descritas para estas rochas na região da Serra da Saudade a processos de retrabalhamento em plataforma dominada por ondas de tempestades.

III - Formação Três Marias: Representa o estágio final da sedimentação do Grupo Bambuí. É marcado pelo forte aumento do aporte sedimentar indicando um evento de caráter regressivo no preenchimento da bacia. Neste contexto foram depositados arenitos com variadas concentrações de matriz pelítica e feldspato. A baixa maturidade tanto textural quanto mineralógica indica deposição rápida próxima da área fonte. De acordo com Chiavegatto (1992), a Formação Três Marias corresponde ao registro sedimentar de ambientes que variam de marinho raso a fluvial e correspondem ao assoreamento final da bacia foreland.

A evolução da edificação da Faixa Brasília provocou nas rochas do Grupo Bambuí uma deformação de caráter rúptil-ductil. Os padrões observados nos dois domínios estruturais identificados, bem como a cinemática da Falha de Galena, indicam um transporte tectônico para E-SE. O desenvolvimento desta estruturação provavelmente foi responsável pelo fim da sedimentação, tornando a área susceptível à ação erosiva.
O próximo ciclo sedimentar da Bacia do São Francisco registrado na região iniciou-se após um hiato de pelo menos 390Ma. Durante o Eocretáceo, o estiramento crustal relacionado à quebra gonduânica e ao desenvolvimento do Atlântico Sul, provocou uma subsidência mecânica na região, que recebeu os sedimentos do Grupo Areado (Campos \& Dardenne 1997b).

Variações altimétricas do Grupo Bambuí associados ao aumento de espessura dos depósitos fanerozóicos e, principalmente, a ocorrência de ruditos da Formação Abaeté permitem interpretar que a tectônica extensional ativa neste período provocou na região o abatimento de um bloco central, limitado a oeste por grandes falhamentos normais e a leste pela reativação de estruturas proterozóicas na região da Falha de Galena. Esta configuração de blocos altos e baixo se assemelha a um sistema graben-horst (Figura 5), que podem também ser observados em escalas de afloramento em diversos pontos investigados (Figura 7).

A calha originada durante esta subsidência foi preenchida, inicialmente, nas bordas das falhas por ruditos e arenitos da Formação Abaeté, depositados em sistemas leques aluviais e fluviais. Posteriormente, a evolução de um sistema flúvio-lacustre na porção central possibilitou a sedimentação de pelitos e, subordinadamente, arenitos da Formação Quiricó. Os arenitos da porção inferior da Formação Três Barras representam a sedimentação de um sistema flúviodeltáico. Por fim, predominou em toda a região um sistema desértico que foi responsável pela sedimentação dos arenitos de dunas eólicas e localmente argilito de interdunas da porção superior da Formação Três Barras, no fim Eocretáceo.

As rochas máficas-ultramáficas do Grupo Mata da Corda registram uma atividade vulcânica no Neocretáceo. Este magmatismo provocou deformações e silicificação nas rochas encaixantes do Grupo Areado. As bombas vulcânicas encontradas nos arenitos da Formação Três Barras superior sugerem que, pelo menos parcialmente, essas unidades foram contemporâneas.

As áreas de ocorrência das rochas vulcânicas sugerem que os derrames e tufos expelidos durante a atividade magmática se concentram próximos às regiões onde houveram as possíveis movimentações normais no cretáceo inferior, sendo provável que estas estruturas também condicionaram a ascensão magmática.

No Grupo Mata da Corda são encontradas, ainda, rochas epiclásticas que registram a erosão dos edifícios vulcânicos. A forte interdigitação entre os litotipos vulcânicos e sedimentares indica que a atividade magmática ocorreu em pulsos isolados por períodos de quiescência.

Agradecimentos - Agradecemos à CODEMIG pelo financiamento de parte do projeto de pesquisa e ao CNPq pela bolsa de mestrado concedida a Daniel Galvão Carnier Fragoso através do Colegiado de Pósgraduação em Geologia IGC/UFMG. 


\section{REFERÊNCIAS}

ALKMIM F.F. BRITO NEVES B.B. ALVES J.A.C. 1993. Arcabouço Tectônico do Cráton do São Francisco - Uma revisão. In: J.M.L. Dominguez, A. Misi (Org.). O Cráton do São Francisco. SBGBA/SE, SGM-BA, p. 45-62.

ALKMIM F.F. \& MARTINS-NETO M.A. 2001. A Bacia Intracratônica do São Francisco: Arcabouço estrutural e cenários evolutivos. In: C.P. Pinto \& M.A. Martins-Neto (eds.) Bacia do São Francisco: Geologia e Recursos Naturais. Belo Horizonte, SBG-MG, 1, p. 9-30.

BAPTISTA M.C. 2004. Estratigrafia e evolução geológica da região de Lagoa Formosa (MG). Dissertação de Mestrado, Instituto de Geociências, Universidade Federal de Minas Gerais, 104 p.

CAMPOS J.E.G. \& DARDENNE M.A. 1997a. Estratigrafia e sedimentação da bacia Sanfranciscana: Uma Revisão. Revista Brasileira Geociências, 27(3): 269-282.

CAMPOS J.E.G. \& DARDENNE M.A. 1997b. Origem e evolução tectônica da Bacia Sanfranciscana. Revista Brasileira Geociências, 27(3):283-294.

CASTRO P.T.A. 1997. Os conglomerados associados ao Grupo Bambuí na porção sudoeste do Cráton do São Francisco. sedimentologia, estratigrafia e implicações tectônicas. Tese de Doutoramento, Inst. de Geociências, Universidade de Brasilia, $262 \mathrm{p}$.

CHANG H.K., MIRANDA F.P., MAGALHÃES E., ALKMIM F.F. 1988. Considerações sobre a evolução tectônica da bacia do São Francisco. In: SBG, Cong. Bras. Geol., 35, Anais, 5: 2076-2090.

CHIAVEGATTO J.R.S. 1992. Análise estratigráfica das seqüências tempestíticas da Formação Três Marias (Proterozóico Superior), na porção meridional da Bacia do São Francisco. Dissertação de Mestrado, Depto. de Geol., Esc. de Minas, Univ. Fed. de Ouro Preto, 216p.

KATTAH, S.S. 1991. Análise Faciológica e Estratigráfica do Jurássico Superior / Cretáceo Inferior na Porção Meridional da Bacia Sanfranciscana, Oeste do Estado de Minas Gerais. Dissertação de Mestrado, Depto. Geol., Escola de Minas, Universidade Federal de Ouro Preto, 227 p.
LIMA O.N.B. 2005. Grupo Bambuí: Estratigrafia regional no Alto Rio São Francisco e geologia dos depósitos fosfáticos da Serra da Saudade - MG. Dissertação de Mestrado, Instituto de Geociências, Universidade Federal de Minas Gerais, 142 p.

LIMA O.N.B, UHLEIN A., BRITTO W. 2007. Estratigrafia do Grupo Bambuí na Serra da Saudade e geologia do depósito fosfático de Cedro do Abaeté, Minas Gerais. Revista Brasileira de Geociências, 37: 204-215.

MARTINS-NETO M.A., CASTRO P.T.A., HERCOS C.M. 1997. O Supergrupo São Francisco(Neoproterozóico) no Cráton do São Francisco em Minas Gerais. Belo Horizonte, $S B G / M G$, Boletim, 14, p. 22-24.

MARTINS-NETO M.A. \& ALKMIM F.F. 2001. Estratigrafia e Evolução Tectônica das Bacias Neoproterozóicas do Paleocontinente São Francisco e suas margens: registros da quebra de Rodinea e colagem de Gondwana. In: C.P. Pinto \& M.A. Martins-Neto (eds.). Bacia do São Francisco: Geologia e Recursos Naturais. Belo Horizonte, SBGMG, 1, p.: 31-54

MORAES L.C., SEER H.J., KATTAH S.S. 1987. Aspectos petroquímicos das rochas vulcânicas alcalinas cretácicas da porção meridional da Bacia Sanfranciscana, MG. In: Congr. Bras.Geoquim., 1, Anais, p. 315-326.

SAWASATO E.Y. 1995. Estruturação da porção meridional da bacia Alto-Sanfranciscana, Cretáceo do Oeste de Minas. Gerais. Dissertação de Mestrado, Departamento de Geologia, Escola de Minas, Universidade Federal de Ouro Preto, 127 p.

RAMSAY J.G. 1967. Folding and fracturing of rocks. McGraw-Hill, New York, $567 \mathrm{p}$.

UHLEIN A., LIMA O.N.B., FANTINEL L.M., BAPTISTA, M.C. 2004. Estratigrafia e evolução geológica do Grupo Bambuí, Minas Gerais. In: SBG, Congresso Brasileiro de Geologia, 42, Roteiro Geológico, Excursão 2, CD-ROM, p. 30-51

UHLEIN, A.; DARDENNE, M A.; SEER, H. J.; MORAES, L. C.; BAPTISTA, M. C.; NOCE, C. M.; FRAGOSO, D. G. C.; DIAS, P. H. A.; MOREIRA, G. C. A Formação Lagoa Formosa e a estratigrafia do Grupo Bambuí em Minas Gerais. In: XLV Congresso Brasileiro de Geologia, 2010, Belém. Anais do XLV Congresso Brasileiro de Geologia, 2010. 